\title{
FEDERALISMO E DIREITOS HUMANOS FUNDAMENTAIS - EVOLUÇÃO HISTÓRICA DO ESTADO DE DIREITO, IDEOLOGIAS POLÍTICAS, GOLPES DE ESTADO E OS FUNDAMENTOS DO ESTADO FEDERAL ${ }^{1}$
}

Caio Gama Mascarenhas ${ }^{2}$

Resumo: Este trabalho visa trazer uma perspectiva do federalismo sob a ótica dos direitos humanos fundamentais. Nesse sentido, pretende-se demonstrar como se deu a evolução histórica do federalismo dual no Estado Liberal de direito ao federalismo cooperativo no Estado Social Democrático de direito. Igualmente, analisam-se quais fatores históricos, políticos e econômicos foram determinantes para a mutação do modelo federativo. Por fim, perquirem-se os fundamentos do federalismo e como se relacionam com os direitos humanos fundamentais. Será usado o método dedutivo/indutivo, por meio da pesquisa bibliográfica e histórica.

Palavras-chave: Dinamogênesis; neofederalismo; desenvolvimento; justiça social; golpe de estado.

\section{FEDERALISM AND FUNDAMENTAL HUMAN RIGHTS - HISTORIC EVOLUTION OF THE RULE OF LAW, POLITICAL IDEOLOGIES AND THE FUNDAMENTALS OF THE FEDERAL STATE}

\begin{abstract}
This paper aims to bring a perspective of federalism from the standpoint of fundamental human rights. From this perspective, it shows how the historical evolution of the dual federalism in the Liberal State to the cooperative federalism in the Social Democratic State occurred. It also analyzes which historical, political and economic factors were determinant for the mutation of the federative model. In a third moment, it discusses about the foundations of federalism and how they relate to fundamental human rights. The deductive/inductive method will be used, through the bibliographical and historical research.
\end{abstract}

Keywords: Dinamogênesis; neofederalism; development; social justice; coup d'etat.

\section{INTRODUÇÃO}

\footnotetext{
${ }^{1}$ Artigo apresentado e aprovado durante o XXVII Congresso Nacional do CONPEDI Porto Alegre/ RS, entre os dias 14 e 16 de Novembro de 2018, no GT “TEORIA E FILOSOFIA DO ESTADO”.

2 Mestrando em Direito pela Universidade Federal de Mato Grosso do Sul (2018-presente). Graduado pela Pontifícia Universidade Católica de Goiás PUC-GO (2009) e especializado em Direito Constitucional e Administrativo pela mesma instituição (2013). Participou do grupo de assessoramento de gabinete de ministro do Superior Tribunal de Justiça atuante na $2^{\mathrm{a}}$ turma de Direito Público (2014-2015). Integrante do grupo de Pesquisas no CNPq - Direito, Políticas Públicas e Desenvolvimento Sustentável. Procurador do Estado do Mato Grosso do Sul (2015- presente). E-mail: caiogm_jus@live.com
} 
A proposta do artigo é trazer uma perspectiva do federalismo sob a ótica dos direitos humanos e fundamentais. As raízes do Estado federal estão vinculadas não somente à teoria geral do estado e à ciência política, mas, outrossim, às várias gerações/dimensões de direitos humanos fundamentais que modificam a estrutura federativa ao longo do tempo.

Algumas questões podem ser levantadas: como se deu a evolução histórica do federalismo dual no Estado Liberal de direito ao federalismo cooperativo no Estado Social Democrático de direito? Quais fatores históricos, políticos e econômicos foram determinantes para a mutação do modelo federativo? Quais são os fundamentos do federalismo e como se relacionam com os direitos humanos fundamentais?

Inicialmente abordar-se-á a evolução histórica do Estado federal de um modelo Dual para o modelo cooperativo e sua relação com as mudanças ocorridas no Estado de direito, segundo os ensinamentos de autores como Paulo Bonavides, José Gomes Canotilho, Manoel Ferreira Filho, José Afonso da Silva, Fábio Comparato, Willian Riker e Fernanda Dias Menezes de Almeida. Aborda-se o federalismo dual no Estado Liberal, passando um federalismo cooperativo no Estado Social de direito e, posteriormente, um federalismo cooperativo no Estado Social democrático de direito.

Por fim, faz-se uma abordagem dos fundamentos do Estado federal e suas conexões com as diversas gerações e dimensões dos Direitos Humanos fundamentais, destacando as categorias de direitos humanos e como se refletem no federalismo. Algumas das doutrinas utilizadas nesse segundo momento são provenientes de Immanuel Kant, Montesquieu, John Hart Ely, Robert Schütze, Vladmir da Silveira e Paulo Bonavides.

Como a estrutura de governo do estado não é exclusividade da área jurídica, faz-se uma abordagem transdisciplinar da matéria com a ciência política, ressaltando fatos e fenômenos político-econômicos históricos.

O trabalho é desenvolvido a partir dos métodos indutivo e dedutivo utilizando de material bibliográfico e documental. Por se tratar de um estudo descritivo e exploratório, será realizado com base na pesquisa bibliográfica e histórica, utilizando-se por vezes do método dedutivo e, outras vezes, do indutivo, principalmente nas críticas e reflexões acerca dos textos normativos. 


\section{EVOLUÇÃO HISTÓRICA - DO FEDERALISMO DUAL NO ESTADO LIBERAL DE DIREITO AO FEDERALISMO COOPERATIVO NO ESTADO SOCIAL DEMOCRÁTICO DE DIREITO}

Somente se pode falar em federalismo com o advento do Estado de direito. No Estado de não direito, não havia espaço para falar limitação do poder do governante em favor dos indivíduos governados. Segundo a lição de Canotilho (1999, p.4), o Estado de direito é aquele cuja atividade é determinada e limitada pelo direito. $\mathrm{O}$ autor define o Estado de não direito como aquele em que "o poder político se proclama desvinculado de limites jurídicos e não reconhece aos indivíduos uma esfera de liberdade ante o poder protegida pelo direito".

$\mathrm{Na}$ origem, o Estado de direito era um conceito tipicamente liberal, nascendo nas constituições liberais burguesas. O Estado liberal de Direito possuía como objetivo fundamental assegurar o princípio da legalidade, segundo o qual toda e qualquer atividade estatal havia de submeter-se à lei. Os atributos básicos do Estado Liberal de Direito foram: a) submissão ao império da lei, cujo conteúdo configurava ato emanado formalmente do Poder Legislativo, composto de representantes do povo; b) divisão de poderes, ressaltando a independência e harmonia entre os poderes legislativo, executivo e judiciário no exercício de suas funções constitucionais; c) declaração e garantia dos direitos individuais. Tais exigências permanecem como fundamentos básicos do Estado de direito, sendo uma conquista da civilização liberal (SILVA, 1988, p. 16).

A Constituição moderna, tal como a norte-americana, é um supremo ato da vontade política de um povo. Enquanto instrumento do Estado de direito, a finalidade da Carta Política moderna é a proteção do indivíduo contra os abusos dos governantes. Por ser uma verdadeira Carta Magna das liberdades, ela deve constar de um documento solene (COMPARATO, 2013, p. 63).

Fábio Comparato (2013, p. 62) assevera que, juntamente com a Declaração dos Direitos do Homem e do Cidadão promulgada pela Assembleia Nacional francesa em 1789, as declarações de direitos norte-americanas constituem as cartas fundamentais de afirmação da autonomia individual. Tal autonomia vinha sendo progressivamente feita na consciência europeia desde fins da Idade Média, assumindo contornos jurídicos definitivos na Europa Ocidental e nos Estados Unidos no final do século XVIII. O estudioso alerta, no entanto, que a perda da proteção familiar, estamental ou religiosa tornou o indivíduo mais vulnerável às

Rev. de Teorias e Filosofias do Estado | e-ISSN: 2525-9652 | Porto Alegre | v. 4 | n. 2 | p. 90 - 110 |

Jul/Dez. 2018 
eventualidades da vida. Conclui dizendo que sociedade liberal ofereceu às classes vulneráveis a segurança da legalidade e nada mais.

Nesse contexto histórico de Estado Liberal de Direito, nasceu o instituto políticoconstitucional chamado Federalismo. A separação de poderes, enquanto garantia constitucional contra o abuso de poder, não abrange somente a clássica tripartição de poderes estatais idealizada por Montesquieu em seu livro De L'Esprit des Lois (1748), mas também a descentralização político-administrativa efetuada através do federalismo ${ }^{3}$.

Para entender os traços do federalismo no Estado Liberal de Direito, necessita-se de entender o contexto em que o instituto nasceu nos Estados Unidos da América. As antigas treze colônias britânicas da América do Norte, independentes a partir de 1776, reuniram-se inicialmente sob a forma de uma confederação. Posteriormente, constituíram-se sob a forma de Estado federal, em 1787. Segundo Fábio Comparato (p. 57, 2013), tal ato "representou o ato inaugural da democracia moderna, combinando, sob o regime constitucional, a representação popular com a limitação de poderes governamentais e o respeito aos direitos humanos".

Três grandes características socioculturais atuaram como fatores predominantes para influenciar a criação do novo Estado federal: a) o ex-núcleo colonial acabou moldando a nação norte-americana em uma sociedade tipicamente burguesa, destacando sua sociedade como um grupo organizado de cidadãos livres, iguais perante a lei e cuja diferenciação interna só podia existir em função da riqueza material; b) a defesa das liberdades individuais e; c) a submissão dos poderes governamentais ao consentimento popular (government by consent) (COMPARATO, 2013, p. 63).

Nesse momento histórico, nasce o federalismo dual em sua forma mais pura e extremada. O federalismo dual caracteriza-se pelo fato de que as esferas de competência dos governos estaduais e o governo federal possuíam limites rígidos. Considerando que, nos Estados Unidos da América, o texto da Constituição enumera poucas competências para a

\footnotetext{
${ }^{3}$ A constitucionalização dos remédios contra o abuso do poder ocorreu através de dois institutos típicos: o da separação dos poderes e o da subordinação de todo poder estatal (e, no limite, também do poder dos próprios órgãos legislativos) ao direito (o chamado "constitucionalisrno"). Por separação dos poderes, entendo - em sentido lato - não apenas a separação vertical das principais funções do Estado entre os órgãos situados no vértice da administração estatal, mas também a separação horizontal entre órgãos centrais e órgãos periféricos nas várias formas de autogoverno, que vão da descentralização político-administrativa até o federalismo (BOBBIO, 1992, p. 62).
}

Rev. de Teorias e Filosofias do Estado | e-ISSN: 2525-9652 | Porto Alegre | v. 4 | n. 2 | p. 90 - 110 | Jul/Dez. 2018 


\section{FEDERALISMO E DIREITOS HUMANOS FUNDAMENTAIS - EVOLUÇÃO HISTÓRICA DO ESTADO DE DIREITO, IDEOLOGIAS POLÍTICAS, GOLPES DE ESTADO E OS FUNDAMENTOS \\ DO ESTADO FEDERAL}

União, havia uma hipertrofia considerável das competências dos Estados-membros inicialmente ${ }^{4}$.

Nos séculos XVIII e XIX, a concepção de federalismo predominava como dualista. O ideal era separar duas esferas de competência de maneira hermética - a da União de um lado, a do Estado-Membro de outro. Daí a repartição horizontal de competências, a previsão de tributos exclusivos (FERREIRA FILHO, 2012, p. 89). Durante tal período, no entanto, variou o grau de poderes e equilíbrio entre o ente central e os entes componentes.

Em um primeiro momento, das duas leis que regem a Federação (autonomia e participação), era a lei da autonomia aquela que se mostrava mais dominadora. Os Estados componentes eram blindados numa posição de força, imperante tanto nos fatos como na doutrina. Foi um período em que filósofo político Tocqueville, diferentemente do que ocorre de fato nos dias atuais, previa um futuro sombrio do sistema federativo. Defendia que o excesso de competências dos Estados-membros colocaria a Federação debaixo da ameaça de eventual dispersão ou desaparecimento (BONAVIDES, 2000, p. 241).

Tal modelo de predomínio de poderes dos Estados-membros provou-se insustentável após determinado tempo. O período anterior à Guerra Civil americana (ou Guerra da Secessão) é marcada por intensos debates políticos sobre a conveniência da manutenção da unidade do Estado federal. Diferenças culturais, econômicas e divergências acerca das práticas escravagistas foram fundamentais para a eclosão da guerra entre os estados do norte e os estados do $\mathrm{sul}^{5}$.

\footnotetext{
${ }^{4}$ No artigo $1^{\circ}$ da constituição norte americana, as competências legislativas da União são enumeradas na seção 8, limitadas na seção 9, enquanto que as vedações de atuação dos Estados são listadas na seção 10. A $10^{\mathrm{a}}$ emenda constitucional tratou de reservar aos estados as competências residuais. Cita-se o texto de tal emenda, ratificada em 1791: "The powers not delegated to the United States by the Constitution, nor prohibited by it to the States, are reserved to the States respectively, or to the people". Disponível em: <https://www.senate.gov/civics/constitution_item/constitution.htm〉. Acesso em 18 maio 2018.

${ }^{5}$ Nas palavras de Vitor Izecksohn: "Os Estados Unidos pertencem ao grupo de países para os quais a ameaça separatista constituiu um elemento central na formação de uma orientação nacionalista e na cristalização da unidade territorial. O período anterior à Guerra Civil é particularmente interessante no que concerne ao debate político sobre a conveniência do estado nacional. Isso se deu no contexto das lutas políticas que levariam à separação dos estados do Sul e a formação de um novo país, ainda que um país de curta duração, os Estados Confederados da América (04/1861 a 04/1865). A presença da escravidão nos estados do sul foi o elemento fundamental para a eclosão da guerra. Ela dividiu a União criada pela Declaração da Independência (1776) e pela Constituição norte-americana (1787) em duas regiões distintas: o Norte livre e o Sul escravista. Essa divisão geográfica levou a uma crescente diferenciação nos níveis de desenvolvimento econômico, do grau de liberdade, da escala de valores e da capacidade de cada região para elaborar, desenvolver e aplicar novas tecnologias aos seus ambientes. No longo prazo esta divisão também permitiu a edificação de visões divergentes sobre o papel do governo, da divisão de poderes e do próprio exercício da democracia em cada uma das regiões. No entanto, a relevância da escravidão como fator explicativo para a explosão da guerra tem sido prioritariamente relacionada à história econômica, ficando em menor relevo o processo de formação do estado norte-americano no período.
}

Rev. de Teorias e Filosofias do Estado | e-ISSN: 2525-9652 | Porto Alegre | v. 4 | n. 2 | p. 90 - 110 | Jul/Dez. 2018 
Passa-se então a um segundo momento do federalismo dual no Estado Liberal de Direito, marcado pelo perfeito equilíbrio entre a União e os Estados federados. A partir de tal período, a própria interpretação acerca das liberdades civis fundamentais passa a ter maior uniformidade $^{6}$ no território norte-americano.

Em tal fase histórica, havia terminado o tormentoso debate teórico entre juristas e políticos: a Constituição Federal era lei ou apenas contrato entre os antigos estados independentes? A resposta teria enormes efeitos para a teoria constitucional. Se fosse lei lei constitucional rígida - daria ao governo central da federação, como sujeito de direito, uma autoridade política inteira, direta e imediata sobre todo o povo da União. Por outro lado, se fosse apenas contrato, haveria tão-somente mera relação jurídica entre a União e os Estados-membros. Segundo tal teoria, o governo central exerceria somente uma jure delegationis - delegação de poderes de Estados livres e soberanos, detentores do direito de secessão, face a temporariedade e dissolubilidade do laço federativo. Vencidos os separatistas na guerra civil norte-americana, prevaleceu a ideia tradicional de um sistema federal uno, indissolúvel e estável. Verificou-se, por conseguinte, um equilíbrio das tendências unionistas com as tendências particularistas de cada Estado componente. Correntes unitaristas harmonizavam-se com as correntes federalistas e forças políticas centrípetas harmonizavamse com as forças políticas centrífugas (BONAVIDES, 2000, p. 242).

Dentro desse segundo período do federalismo dual, é promulgada a primeira constituição republicana no Brasil. A Constituição de 1891 seguiu a tendência descentralizadora do princípio republicano. Por essa Constituição, no entanto, recursos públicos foram canalizados para alguns poucos estados, denotando que a federação brasileira nasceu "sob a égide da concentração de recursos em poucos estados e escassas relações existiam entre os entes constitutivos da federação, caracterizando esse período como o de uma

Da perspectiva aqui esposada, o separatismo foi um elemento fundamental para o processo de construção do estado nacional nos Estados Unidos, principalmente porque a luta pelo controle do estado nacional foi um importante componente da crise que precedeu o início das hostilidades, como pretendo demonstrar no decorrer deste artigo. Estas questões serão exploradas através da análise das relações entre a escravidão e o sistema federal no contexto do debate político anterior à Guerra Civil. As discussões aqui apresentadas tomam como ponto de partida os argumentos de recentes contribuições que analisaram o debate sobre a escravidão e a guerra como componentes importantes do processo de construção do estado nacional norte-americano" (2003, p. 47).

${ }^{6}$ No momento anterior à Guerra da Secessão nos Estados Unidos, enquanto os nortistas eram contrários à escravidão, os sulistas tentavam harmonizar os conceitos de liberdade e escravidão, apelando para uma vertente conservadora da ideologia republicana. Segundo tal ideologia, a escravidão somente fortalecia o senso de igualdade entre os homens brancos, limitando o trabalho desqualificado a uma raça inferior. O homem branco estaria muito acima do status dos escravos. As demandas dos brancos pobres não eram um problema nos estados do sul. Segundo Joseph E. Brown, Governador da Georgia na época da secessão, a escravidão seria "o melhor governo do homem pobre" (IZECKSOHN, 2003, p. 53).

Rev. de Teorias e Filosofias do Estado | e-ISSN: 2525-9652 | Porto Alegre | v. 4 | n. 2 | p. 90 - 110 | Jul/Dez. 2018 


\section{FEDERALISMO E DIREITOS HUMANOS FUNDAMENTAIS - EVOLUÇÃO HISTÓRICA DO ESTADO DE DIREITO, IDEOLOGIAS POLÍTICAS, GOLPES DE ESTADO E OS FUNDAMENTOS \\ DO ESTADO FEDERAL}

federação isolada" (SOUZA, 2005, p. 107). Tal constituição manteve, em seu texto, o apego à concepção individualista dos direitos fundamentais já presente na Constituição de 1824 (FERREIRA FILHO, 2012, p. 321).

Após a Primeira Guerra Mundial, passa-se então do Estado Liberal de Direito para o Estado Social de Direito, modificando igualmente o modelo de sistema federativo existente (FERREIRA FILHO, 2012, p. 89). O individualismo e abstencionismo estatal do Estado liberal provocaram imensas injustiças. Os movimentos sociais dos séculos XIX e XX, revelando a insuficiência das liberdades burguesas, permitiram que se tivesse consciência da necessidade da justiça social. O Estado social de Direito objetiva a correção do individualismo clássico liberal mediante a afirmação dos chamados direitos sociais e realização de objetivos de justiça social. Possui o escopo de compatibilizar, em um mesmo sistema, dois elementos: o capitalismo, como forma de produção, e a consecução do bemestar social geral, servindo de base ao neocapitalismo típico do Welfare State (SILVA, 1988, p. 18). Ressalta-se que o Estado Social somente será Estado de direito se não abandonar as conquistas do Estado Liberal de Direito, adicionando às liberdades civis e políticas conquistadas aos direitos sociais econômicos e culturais desse novo estágio (CANOTILHO, 1998, p. 14).

A partir desse período, concebe-se o federalismo como cooperativo. O ideal da forma federativa de Estado é coordenar as duas esferas, sob evidentemente administração da União. Daí surgem a repartição vertical de competência e os tributos partilhados entre entes federativos (FERREIRA FILHO, 2012, p. 89).

Essa fase do federalismo cooperativo, que Paulo Bonavides (2000, p. 245) denomina como "neofederalismo", rompe o equilíbrio observado no período anterior entre os dois princípios fundamentais da autonomia e da participação. Predomina-se, a partir de então, a participação dos entes federados na administração nacional, enquanto que há um significativo declínio da autonomia. As previsões de Tocqueville não se concretizaram - houve o excesso de poderes federais em detrimento dos poderes estaduais. O enfraquecimento da Federação e seu iminente perigo de extinção dar-se-ia, segundo os críticos do modelo atual, por motivos inversos daqueles imaginados pelo pensador francês. Os que defendem a crise atual do federalismo assumem, portanto, um tom diferente ${ }^{7}$.

\footnotetext{
${ }^{7}$ Não há como aprofundar de maneira satisfatória no tormentoso tema que é a crise do federalismo. Somente a crise do federalismo sob a visão de Paulo Bonavides, por exemplo, merece um trabalho próprio. Na década de
}

Rev. de Teorias e Filosofias do Estado | e-ISSN: 2525-9652 | Porto Alegre | v. 4 | n. 2 | p. 90 - 110 | Jul/Dez. 2018 
Nos Estados Unidos, ocorria o fenômeno político do New Deal, caracterizado pelo implemento de uma série de políticas públicas econômicas e assistencialistas entre 1933 e 1937, sob o governo do Presidente Franklin Delano Roosevelt. Willian Riker (1987, p.11), renomado cientista político americano, explica que o estatismo próprio do New Deal implicava que o governo federal deveria atuar livremente. Como o federalismo restringia o governo central por meio de conflitos entre os estados e a nação, o ideal para o new dealer era buscar eliminar o federalismo. Por outro lado, os opositores defendiam que a finalidade liberal de proteger direitos de abusos estatais justificava limites como o federalismo e a tripartição de poderes.

Na Alemanha, foi promulgada a Constituição de Weimar em 1919 - um marco histórico na defesa de dos direitos sociais. Tal constituição adotava um modelo de federalismo de cooperação, destacando sua função de efetivação de direitos humanos de segunda dimensão. Tal constituição assegurava em seu art. 146, por exemplo, um sistema de escolaridade obrigatória por meio de cooperação financeira e técnica entre Estado central (Reich), os Estados federados (Länder) e os Municípios (COMPARATO, 2013, p. 106).

Essa nova dimensão social do Estado e dos direitos também se manifestou no federalismo brasileiro. A cooperação financeira entre as entidades autônomas da Federação, chamada federalismo cooperativo, começou a desenvolver-se a partir da segunda dimensão de direitos humanos fundamentais. No ordenamento constitucional brasileiro, desenvolveu-se a partir da Constituição de 1934 (art. 9º), mas foi a Constituição de 1937 que inaugurou a prática da participação na receita de tributos (Lei constitucional 4/40). A Constituição de 1946 alargou a técnica de cooperação financeira, que a Constituição de 1967 procurou racionalizar. Tais técnicas e experiências foram incorporadas, expandidas e aperfeiçoadas pela Constituição de 1988 (SILVA, 2014, p. 741-742).

Voltando para a questão do Estado de direito, reitera-se que nem sempre o Estado social e o estado liberal respeitaram aos direitos fundamentais. Nesse sentido, é só se lembrar

70, o constitucionalista já criticava os efeitos da hipertrofia do Executivo em pleno regime militar (AI-5). Vindicava que o Brasil vivia 90 anos de "Estado unitário de fato". Segundo sua visão, a legitimidade constitucional do federalismo não se refletia na realidade política, criticando, inclusive, o termo "federalismo de cooperação" associado ao típico caráter de Estado unitário centralizador dos regimes ditatoriais brasileiros do século XX. Baseando-se no sucesso da SUDENE, apontava como solução para tal crise política o chamado federalismo de regiões (BONAVIDES, 1980, p. 115-126). Após o advento da constituição democrática de 1988, atenuou suas críticas ao sistema federativo brasileiro, mas ainda defendendo uma crise federativa no nosso sistema (BONAVIDES, 2000, p. 242-246). O federalismo de regiões foi uma bandeira defendida pelo autor sempre com muito vigor - isso dos anos 70 (BONAVIDES, 1980, p. 120-126) até os tempos atuais (BONAVIDES, 2004, p. 258).

Rev. de Teorias e Filosofias do Estado | e-ISSN: 2525-9652 | Porto Alegre | v. 4 | n. 2 | p. 90 - 110 | Jul/Dez. 2018 


\section{FEDERALISMO E DIREITOS HUMANOS FUNDAMENTAIS - EVOLUÇÃO HISTÓRICA DO ESTADO DE DIREITO, IDEOLOGIAS POLÍTICAS, GOLPES DE ESTADO E OS FUNDAMENTOS \\ DO ESTADO FEDERAL}

dos regimes totalitaristas ditatoriais do nazismo e fascismo e, no caso do Estado Liberal, da luta contra a abolição da escravidão pelos Estados do Sul na América do Norte. A questão da democracia e dos direitos políticos não foi diferente. O manifesto comunista de Karl Marx e Friedrich Engels, base ideológica do Estado socialista, defende a ditadura do proletariado, mediante eliminação da classe burguesa e de sua ideologia política (MARX; ENGELS, 2015, p. 41-42).

No Estado Liberal clássico, a participação política não possuía um peso considerável. A ideia de que a liberdade negativa tem precedência sobre a participação política (liberdade positiva) é um dos preceitos básicos do liberalismo político clássico. Em tal contexto, as liberdades políticas teriam uma importância intrínseca menor do que a liberdade pessoal e de consciência (CANOTILHO, 1999, p. 10).

O federalismo, como verdadeiro mecanismo de limitação de poderes do Ente central da federação, é uma das primeiras vítimas dos regimes totalitários. Tais regimes não toleram o sistema federalista, que implica a divisão espacial de poderes e oposição à concentração típica de competências própria dos ideais tirânicos. Na Alemanha de Adolph Hitler, uma das primeiras medidas do nacional-socialismo do terceiro reich foi abolir parlamentos estaduais regionais e a Reichsrat (casa federal superior) em janeiro de 1934 (EVANS, 2005, p. 109). Assim, os Estados totalitários extinguiam ou inutilizavam o sistema federalista preexistentes em suas nações. Na visão de muitos autores, por exemplo, o comunismo seria "totalmente incompatível com o sistema federativo, já que pressupõe a ditadura do proletariado, exercida através do partido comunista" (TAVARES, 2013, p. 788).

Pablo Ramella (1971, p. 45), constitucionalista argentino, analisa o desenfreado crescimento do poder do ente central do Estado federal nos países latino-americanos. Em três grupos, ele identifica e separa as causas da hipertrofia dos poderes do ente central em detrimento dos entes subnacionais: as causas naturais; as causas decorrentes da inércia dos entes federados subnacionais; e as causas advindas da corrupção do sistema. Nas causas naturais, estão as necessidades típicas da ordem social e econômica do Estado contemporâneo, impondo a adoção de critérios nacionais uniformes e uma constante interação harmônica e cooperativa dos entes estaduais com o ente nacional. Dentro das causas decorrentes de inércia dos entes federados subnacionais, encontra-se a inoperância dos governos provinciais na busca de soluções locais para problemas que não dependeriam de auxilio do ente central, adotando uma postura de cômoda submissão ao poder federal, do qual

Rev. de Teorias e Filosofias do Estado | e-ISSN: 2525-9652 | Porto Alegre | v. 4 | n. 2 | p. 90 - 110 | Jul/Dez. 2018 
tudo se espera. Entre as causas de corrupção do sistema, figuram o abuso de institutos constitucionais como a intervenção federal para a imposição das vontades do presidente da república e o recurso a golpes de estados, que levam o chefe do poder executivo federal a assumir todos os poderes políticos, eliminando a autonomia dos entes federados subnacionais.

No Brasil, a tendência unitarista iniciada em 1930 iniciou um longo processo de dilaceração da autonomia dos estados. No campo constitucional, a Constituição de 1934 dilatou os poderes do presidente da república, sendo que a extensão de tais poderes era incompatível com o princípio da autonomia política dos entes federativos. A constituição de 1937 também previa em seu texto o federalismo, mas era classificado por Raul Machado Horta (1967, p. 47) como um "federalismo nominal", que se curvava a decretos-leis editados pelo presidente da república ${ }^{8}$. A constituição federal de 1946 iniciou um período de redemocratização da nação brasileira, aperfeiçoando as técnicas do federalismo fiscal cooperativo ${ }^{9}$. Foi interrompida, no entanto, pela constituição de 1967/69. O regime militar vigente a partir de tal data fez com que Paulo Bonavides (1980, p. 120) afirmasse a existência, no federalismo nacional, de "mais unitarismo no Brasil do que em todos os Estados unitários membros da Comunidade europeia”. A Constituição de 1967-1969, juntamente com a reforma tributária de 1966, marcou período de centralização de poder político e tributário na esfera federal, afetando o federalismo e suas instituições ${ }^{10}$ (SOUZA, 2005, p. 108). Manoel Ferreira Filho (2012, p. 92) explica que, em tal período, muitos consideravam o modelo da época como "federalismo de integração", denotando a preponderância dos poderes do Governo federal.

\footnotetext{
${ }^{8}$ Durante a Constituição de 1937, Vargas fechou o Congresso Nacional e as assembleias estaduais, substituindo os governadores eleitos por interventores. Há um consenso de que uma das principais razões do golpe seria neutralizar a importância dos interesses regionais com o escopo de construir a unidade política e administrativa necessária para promover a chamada modernização social e econômica do país. Um dos atos mais simbólicos de Getúlio Vargas contra os interesses regionais foi queimar todas as bandeiras estaduais em praça pública (SOUZA, 2005, p. 108).

${ }^{9}$ Nas palavras de Celina Souza (2005, p. 108): “A Constituição de 1946 introduziu o primeiro mecanismo de transferências intergovernamentais da esfera federal para as municipais, excluídos os estados, na tentativa de diminuir os desequilíbrios verticais de receita, mas o critério de transferência não continha nenhum mecanismo de equalização fiscal, dado que consistia em dividir o montante a ser transferido pelo número de municípios existentes".

${ }^{10}$ Apesar das limitações políticas, houve avanço das técnicas de cooperação fiscal durante a vigência da Constituição de 67. Celina Souza (2005, p. 108) explica: "apesar da centralização dos recursos financeiros, foi a reforma tributária dos militares que promoveu o primeiro sistema de transferência intergovernamental de recursos da esfera federal para as subnacionais, por meio dos fundos de participação (Fundo de Participação dos Estados (FPE) e Fundo de Participação dos Municípios (FPM). O critério de distribuição abandonou a repartição uniforme entre os entes constitutivos, passando a incorporar o objetivo de maior equalização fiscal pela adoção do critério de população e inverso da renda per capita. No regime militar, as esferas subnacionais também recebiam as chamadas transferências negociadas, que cresceram significativamente no período".
} 


\section{FEDERALISMO E DIREITOS HUMANOS FUNDAMENTAIS - EVOLUÇÃO HISTÓRICA DO ESTADO DE DIREITO, IDEOLOGIAS POLÍTICAS, GOLPES DE ESTADO E OS FUNDAMENTOS \\ DO ESTADO FEDERAL}

Surge então a figura do Estado democrático de direito. A configuração do Estado democrático de direito não significa apenas unir formalmente os conceitos de Estado democrático (fundado na soberania popular) e Estado de direito (fundado nas liberdades públicas). Consiste, em verdade, na criação de um conceito novo, levando em conta os conceitos dos elementos componentes, mas os superando. Isto porquanto incorpora um componente revolucionário de transformação do status quo. O objetivo fundamental do Estado democrático de direito é a superação das desigualdades sociais e regionais, instaurando um regime democrático que realize a justiça social. (SILVA, p. 20, 1988).

O reencontro do ordenamento constitucional brasileiro com a democracia ressuscitou a forma de Estado federal. Manoel Ferreira Filho (2012, p. 92) aduz que a Constituição de 1988 confere maior autonomia aos Estados-Membros almejando um reequilíbrio federativo. A expansão da autonomia estadual abandona a ideia de federalismo de integração, prevalecendo a ideia de cooperação.

A história da formação de cada Estado, como se viu, molda o sistema federalista de cada país, inexistindo modelos federalistas idênticos no mundo atual. O sistema de distribuição de competências, por exemplo, pode assumir estratégias diversas conforme cada Estado ou momento constitucional. O resultado de tal distribuição constitucional de competências entre os estados-membros definirá se o federalismo será simétrico ou assimétrico. A tradição federalista de países do continente americano tem se mostrado tendente para o federalismo simétrico $^{11}$. Por outro lado, alguns Estados regionais do continente europeu possuem regras de competência que mais se aproximam de um federalismo assimétrico ${ }^{12}$. Mesmo os Estados Federais simétricos possuem grande variação entre si. O Brasil, por exemplo, adotou o critério da predominância do interesse (geral,

\footnotetext{
${ }^{11}$ Celina Souza faz um comparativo entre o federalismo brasileiro e o de outros países do continente americano: "Do ponto de vista constitucional, todas as unidades constitutivas possuem poderes e competências iguais, como ocorre nos EUA e no México. Nesse sentido, o Brasil adotou um modelo de federalismo simétrico em uma federação assimétrica. Dois fatores fortalecem ainda mais esse modelo simétrico. O primeiro é que as regras sobre as competências, recursos e políticas públicas das entidades subnacionais são capítulos detalhados da Constituição, deixando pouca margem de manobra para iniciativas específicas. O segundo é que o Supremo Tribunal Federal (STF) vem decidindo sistematicamente que as constituições e as leis estaduais reflitam os dispositivos federais ou são monopólios federais, o que impõe uma hierarquia das normas constitucionais e legais, apesar da Constituição não explicitar tal princípio" (SOUZA, 2005, p. 105).

${ }^{12}$ É o caso da Itália e da Espanha (CONTI, 2010, p. 16). Na Itália, destaca-se o artigo 116 da constituição, que prevê formas e condições particulares de autonomia para algumas regiões, conforme os respetivos estatutos especiais adotados com a lei constitucional. Constituição disponível no seguinte link: <https://www.senato.it/application/xmanager/projects/leg18/file/repository/relazioni/libreria/novita/XVII/COST _PORTOGHESE.pdf>. Acesso em 18 maio 2018.
}

Rev. de Teorias e Filosofias do Estado | e-ISSN: 2525-9652 | Porto Alegre | v. 4 | n. 2 | p. 90 - 110 | Jul/Dez. 2018 
regional ou local) na repartição de competências entre União, Estados e Municípios (MORAES, 2009, p. 2009). Nos Estados Unidos, a situação é outra. Enquanto competências legislativas em matéria penal e de família são de interesse geral no ordenamento brasileiro (art. 22, I, da Constituição), tais questões são competências residuais no ordenamento jurídico norte-americano - ficando a cargo quase que exclusivamente dos Estados-membros (SPIRO, 1997, p. 568).

A história tem demonstrado, portanto, que o federalismo assume formas diferentes conforme o pensamento político predominante na época e as novas dimensões de direitos que se pretende proteger. O fundamento principal do Estado federal é a garantia de direitos humanos fundamentais, não podendo (nem devendo) o instituto afastar-se desse pressuposto lógico constitucional.

\section{FUNDAMENTOS DO ESTADO FEDERAL E A PROTEÇÃO DOS DIREITOS HUMANOS FUNDAMENTAIS}

Inicialmente, deve-se ter em conta que a teoria constitucional busca respostas para questões políticas fundamentais que afetam os entes constitutivos da federação, tais como “quem governa, como se governa e quem deveria governar" (SOUZA, 2005, p. 105). Cumpre perquirir: por que estados nacionais se associariam? Robert Schütze (2009, p. 20) explica que há duas razões para tanto: uma de ordem particular, fundada na doutrina de Montesquieu; e outra de ordem universal, fundada na doutrina de Kant.

A ideia de ordem particular é proveniente de Montesquieu. Segundo esse teórico, se uma república é muito pequena, é destruída por forças estrangeiras. Por outro lado, se é muito extensa, é destruída por forças internas. Para superar tal dificuldade, seria necessário fazer uma associação entre repúblicas. Tal entidade associativa "goza da excelência do governo interior de cada uma; e, quanto ao exterior, possui, pela força da associação, todas as vantagens das grandes monarquias" (SECONDAT, 1996, p. 141-142).

A ideia de razão universalista é oriunda de Immanuel Kant. O filósofo defendia que a própria ideia de direito internacional pressupunha uma "federação" entre estados soberanos. Tal federação não se propõe obter o poder do Estado, mas apenas manter e garantir a paz entre Estados federados (KANT, 2008, p. 17-18).

Percebe-se então a influência do direito à paz na formação de Confederações e do próprio Estado federal. Reitera-se que o principal propósito dos fundadores da Constituição

Rev. de Teorias e Filosofias do Estado | e-ISSN: 2525-9652 | Porto Alegre | v. 4 | n. 2 | p. 90 - 110 |

Jul/Dez. 2018 


\section{FEDERALISMO E DIREITOS HUMANOS FUNDAMENTAIS - EVOLUÇÃO HISTÓRICA DO ESTADO DE DIREITO, IDEOLOGIAS POLÍTICAS, GOLPES DE ESTADO E OS FUNDAMENTOS \\ DO ESTADO FEDERAL}

norte-americana era proteger as liberdades civis da tirania do Governo por meio da divisão espacial do poder em Estado federal e da separação de poderes em legislativo, judiciário e executivo (ELY, 1996, p. 31). O fato é que do federalismo se espera uma garantia de liberdade e de eficiência ${ }^{13}$. Para este fim foi o sistema idealizado (ALMEIDA, 2013, p. 30).

Os compromissos federalistas foram contraídos historicamente juntamente com ideais de um poder representativo, constitucional, limitado e republicano. Contempla a liberdade nas instituições e no cidadão, sendo intrinsecamente descentralizador. Exprime, como nenhum outro, a ideia de self government, do império da lei, da autodeterminação política, social e econômica de coletividades livres e atuantes. Possui, portanto, os ideais de Estado de direito, regime representativo, legitimidade, poder responsável em sua essência e organização (BONAVIDES, 1980, p. 117).

Amaro Cavalcanti, ministro da Suprema Corte brasileira entre 1906 e 1914, enumerava as vantagens presentes no federalismo: a) harmonização entre interesses gerais e locais; b) maior adaptação à diversidade de etnias, religiões, costumes e tradições históricas; c) repartição do progresso em um governo descentralizado; d) prevenção do despotismo; e) maior segurança aos Estados-membros; e) amenização da carga decisória do poder federal, deixando este voltado a interesses nacionais; f) maior proximidade do povo aos centros de poder (CAVALCANTI, 1900, p. 64).

Não se deve olvidar da dimensão cultural do federalismo. Uma das principais vantagens do Estado federal em detrimento do Estado unitário é a ideia de que as tradições regionais militam contra a fusão de Estados individuais em uma organização unitária. Fortalece-se, desta forma, o sentimento de defesa das diferenças culturais das diversas entidades dentro da estrutura associativa (ALMEIDA, 2013, p. 6). Não é por outro motivo que países como a İndia, com uma imensa pluralidade cultural dentro de um mesmo território nacional, geralmente adotam a forma federativa de Estado ${ }^{14}$.

A função de garantia da democracia participativa dentro do Estado federal também tem sido fortemente ressaltada na era moderna. Há efetiva multiplicação de círculos de

\footnotetext{
${ }^{13}$ O Estado Federal surge para a História como um passo adiante na unificação de interesses convergentes. Buscam eles institucionalizar-se por um modo mais perfeito e eficaz sob a forma de comunhão perpetua e indissolúvel, capaz de exprimir os altos valores da solidariedade, do amparo mútuo, do respeito, da colaboração e da liberdade (BONAVIDES, 1980, p. 116-117).

14 "Para a Índia independente a opção pelo federalismo era mais natural, consideradas suas condições peculiares de país com vasta extensão territorial, imensa diversidade de etnias, religiões, idiomas e profundos desníveis de desenvolvimento econômico" (ALMEIDA, 2013, p. 36).
}

Rev. de Teorias e Filosofias do Estado | e-ISSN: 2525-9652 | Porto Alegre | v. 4 | n. 2 | p. 90 - 110 | Jul/Dez. 2018 
decisões políticas em que o cidadão fica próximo do poder. O federalismo almeja fazer dos Estados laboratórios para o desenvolvimento de novas ideias sociais, econômicas e políticas retomando o mesmo dilema que se teve de enfrentar em relação à liberdade e eficiência na origem do instituto. Segundo Fernanda Dias Menezes de Almeida:

\begin{abstract}
Esse dilema está em obter-se uma composição de forças equilibradas, sem menosprezo ao papel que deve caber a cada parceiro: à União o exercício dos poderes gerais que dizem com os aspectos unitários da federação e que hoje, em atenção às exigências do Estado de bem-estar, devem necessariamente incluir a direção nacional da economia com vistas a um desenvolvimento nacional harmônico; aos Estados a implementação das políticas gerais, cabendo-lhes descodifica-las e adaptá-las às peculiaridades de cada um, sem prejuízo do exercício de poderes próprios que vivifiquem sua autonomia" (ALMEIDA, 2013, p. 30).
\end{abstract}

Nesse sentido, Paulo Bonavides (1980, p. 117) defende que a federação faz do exercício da imaginação "um poderoso instrumento de criatividade e impulso às iniciativas fecundas dos cidadãos". O Estado federal surge com o Estado liberal de direito e com os direitos de primeira dimensão. Toda a primeira dimensão (ou geração) de direitos humanos, presente nas normas e declarações produzidas pelos Estados Unidos e pela Revolução Francesa, é formada de direitos que protegem as liberdades civis e políticas dos cidadãos contra a tirania dos órgãos estatais (COMPARATO, 2013, p. 33). Liberdades típicas de um Estado Liberal.

Durante esse primeiro período, particularidades históricas em seu surgimento fazem com que o federalismo brasileiro possua um desenho distinto de outras federações, principalmente em relação à unidade política de seu território ${ }^{15}$. O Brasil, seguindo a tendência mundial, incorporou as liberdades civis e políticas nos textos de suas duas primeiras constituições (artigo 179 da Carta de 1824 e artigo 72 da Carta de 1891).

$\mathrm{Na}$ Constituição dos Estados Unidos da América, as liberdades civis e políticas dos norte-americanos estão listadas no Bill of Rights, que é constituído pelas dez primeiras

\footnotetext{
15 "O sistema federal foi introduzido em 1889 e detalhado na Constituição de 1891. Como sabemos, e diferentemente de muitas federações, a brasileira nunca foi uma resposta às clivagens sociais decorrentes de conflitos étnicos, linguísticos ou religiosos. Movimentos separatistas ocorreram apenas durante o período colonial e no início do século XIX a unidade do país não era questionada. Por isso, as constituições brasileiras não preveem regras para a secessão e a de 1988 ainda estabelece que nenhuma emenda constitucional pode abolir a 'forma federativa de Estado'. Dado que a unidade do país não se constitui em ameaça, as constituições sempre declararam que 'todo o poder emana do povo' e não da nação, do Estado ou das unidades constitutivas da federação, como ocorre em muitos países federais, sinalizando que o sistema federativo brasileiro está assentado no princípio do individualismo e não no das instituições coletivas. Nesse sentido, o constitucionalismo brasileiro aproxima-se da tradição norte-americana, em que, baseada na concepção lockeana, os direitos fundamentais têm sua origem nos indivíduos, distanciando-se da tradição da Europa continental, onde o Estado é a fonte dos direitos fundamentais" (SOUZA, 2005, p. 106)
}

Rev. de Teorias e Filosofias do Estado | e-ISSN: 2525-9652 | Porto Alegre | v. 4 | n. 2 | p. 90 - 110 | Jul/Dez. 2018 


\title{
FEDERALISMO E DIREITOS HUMANOS FUNDAMENTAIS - EVOLUÇÃO HISTÓRICA DO ESTADO DE DIREITO, IDEOLOGIAS POLÍTICAS, GOLPES DE ESTADO E OS FUNDAMENTOS \\ DO ESTADO FEDERAL
}

emendas constitucionais (COMPARATO, 2013, p. 67). Foi nos Estados Unidos, berço do federalismo clássico, que a autonomia constitucional dos estados-membros constituiu um óbice à tutela de direitos humanos fundamentais pela primeira vez, em claro desvio de finalidade do instituto. Segundo o ensinamento de Fábio Konder Comparato:

\begin{abstract}
Em uma decisão de 1833, a Suprema Corte dos Estados Unidos julgou que essas emendas não se aplicariam aos Estados federados, pois elas foram concebidas originalmente, e assim ratificadas, como limitações tão só aos poderes da União Federal. Ao deflagrar-se a guerra civil em 1860, ficou claro que essa interpretação equivalia a denegar, praticamente, a qualidade de fundamentais aos direitos aí declarados, pois se a abolição da escravatura não vem afirmada explicitamente em nenhuma das dez emendas, e se os Estados, por conseguinte, eram legitimados a manter o instituto nefando, logicamente a legislação estadual tampouco ficaria vinculada ao respeito dos demais direitos aí declarados. Convém lembrar que em 1857, portanto às vésperas da guerra civil, a Suprema Corte quase anulou o princípio da supremacia do Judiciário perante os outros Poderes, na guarda da Constituição, ao julgar que um escravo, introduzido no território de um Estado que proibira a escravidão, nem por isso perdia a sua condição servil. Essa situação anômala só veio a ser corrigida com a promulgação da $14^{\mathrm{a}}$ emenda, em 1868. Declarou-se, então, que "nenhum Estado fará ou executará nenhuma lei, com efeito de reduzir as prerrogativas ou imunidades dos cidadãos dos Estados Unidos; nem tampouco Estado algum privará uma pessoa de sua vida, liberdade ou bens, sem o devido processo jurídico (without due process of law); nem denegará a alguma pessoa, dentro de sua jurisdição, a igual proteção das leis (COMPARATO, 2013, p. 67-68)
\end{abstract}

A preocupação da Constituição Norte-americana de 1787 com a proteção do direito à propriedade foi tão significativa, que seu texto chegou a prever uma garantia constitucional aos proprietários de escravos ${ }^{16}$ (BERCOVICI, 2013, p. 117). O julgado mais famoso mais famoso sobre essa cláusula constitucional foi o Dred Scott v. Sandford ${ }^{17}$, que fez prevalecer normas estaduais escravagistas em detrimento dos direitos à liberdade e dignidade humana.

Em tal momento histórico, percebeu-se a necessidade de limitar o princípio da autonomia dos estados-membros no modelo federalista, denotando um caráter individualista

\footnotetext{
${ }^{16}$ É o que dizia a seção 2 do artigo IV , denominada "fugitive slave clause": "No person held to service or labor in one State, under the laws thereof, escaping into another, shall in consequence of any law or regulation therein, be discharged from such service or labour, but shall be delivered up to claim of the party whom such service or labour may be due".

17 "Dred Scott era um escravo do Missouri que foi com seu proprietário, John Emerson, para um Estado livre (Illinois) e, depois, para um território federal livre (Minnesota), retornando posteriormente ao Missouri com seu dono. Em 1846, Scott e sua esposa processaram o seu proprietário (que, a partir de 1853, passou a ser John Sanford, executor do testamento de Emerson), alegando que o período de tempo que passaram em território livre os teria tornado pessoas livres. O julgamento da demanda foi bem sucedido na corte local, mas revertido na Suprema Corte de Missouri em 1852. Dred Scott, então, impetrou, em 1854, a mesma ação na justiça federal, agora contra Sanford, e foi esta ação que chegou à Suprema Corte, sendo recebida em 30 de dezembro de 1854. A Suprema Corte, entre os dias 6 e 7 de março de 1857, liderada pelo Chief of Justice Roger B. Taney, negou a apelação de Dred Scott por sete votos a dois (os votos dissidentes, que garantiam a liberdade de Dred Scott e sua esposa, foram dados por John McLean e Benjamin R. Curtis)" (BERCOVICI, 2013, p. 118-119).
}

Rev. de Teorias e Filosofias do Estado | e-ISSN: 2525-9652 | Porto Alegre | v. 4 | n. 2 | p. 90 - 110 | Jul/Dez. 2018 
do Estado de direito - em detrimento do conceito organicista de sociedade anterior ao próprio Estado de direito $^{18}$.

Com o passar do tempo, novos direitos vão surgindo - dessa vez de cunho social, econômico e cultural. Tais direitos, considerados como direitos de segunda dimensão/geração, acabam modificando a estrutura federativa do Estado. Um exemplo disso é o direito à educação, estruturado em federalismo cooperativo na Constituição de Weimar de 1919. Diferentemente da liberdade e igualdade formal (tutelados pelo federalismo dualista dos fundadores americanos), o direito à educação - enquanto direito da pessoa humana e obrigação do Estado e sociedade - não possui a mesma proteção histórica da doutrina jus naturalista, sendo uma construção teórica mais recente (BOBBIO, 1992, p. 36). Inicialmente, o direito à educação era um mero valor abstrato em posição suspensa (dimensão présóciojurídica). A partir do momento em que o valor da educação passou a fazer parte do sentimento axiológico da sociedade, começou a existir na realidade social. Adentrando no interesse social, incumbiu ao direito proteger e garantir a educação mediante a sua inclusão no ordenamento jurídico pela dinamogenesis ${ }^{19}$.

Nesse momento histórico, no entanto, os Estados Sociais, não raro, desrespeitavam as liberdades civis e políticas já conquistadas na primeira geração/dimensão de direitos. Tal situação refletiu-se nos modelos de Estado federal adotados em tais nações.

Logo após o término da segunda guerra mundial, surge a terceira geração/dimensão de direitos humanos. No ano de 1945, representantes de 51 países assinaram a Carta criadora da Organização das Nações Unidas (ONU) em São Francisco (EUA). A partir daí, direitos de solidariedade são adicionados às dimensões/gerações de direito preexistentes no ordenamento jurídico mundial, completando a associação as três dimensões/gerações de direitos humanos

\footnotetext{
${ }^{18}$ Sobre as concepções individualistas e organicistas de sociedade, Norberto Bobbio esclarece: “[...] o primeiro ângulo é o dos governantes. O objeto da política foi sempre o governo, o bom governo ou o mau governo, ou como se conquista o poder e como ele é exercido, quais são as funções dos magistrados, quais são os poderes atribuídos ao governo e como se distinguem e interagem entre si, como se fazem as leis e como se faz para que sejam respeitadas, como se declaram as guerras e se pactua a paz, como se nomeiam os ministros e os embaixadores. [...]. Tratar-se-ia de nada menos do que de dar conta do nascimento da concepção individualista da sociedade e da história, que é a antítese radical da concepção organicista , segundo a qual — para repetir uma afirmação de Aristóteles que será retomada por Hegel — o todo (a sociedade) é anterior as suas partes. invertendo essa relação entre o todo e as partes, a concepção individualista da sociedade e da história afirma que primeiro vem o indivíduo, não o indivíduo para a sociedade” (BOBBIO, 1992, p. 51).

${ }^{19} \mathrm{O}$ nome de tal processo é dinamogenesis. Vladmir da Silveira e Maria Rocasolano (2010, p. 196) explicam que: "Por intermédio da normatização, os valores, que já são, vivem. Saltam do plano ideal (sentimental) para o real (normatizado) porque se pode exigi-los, garanti-los e protegê-los. Pode-se dizer então que o sentimento axiológico é uma ordem valorativa que a sociedade estima como valiosa, define e, por essa razão, sente - e em caso de perigo defenderá apaixonadamente.”.
}

Rev. de Teorias e Filosofias do Estado | e-ISSN: 2525-9652 | Porto Alegre | v. 4 | n. 2 | p. 90 - 110 | Jul/Dez. 2018 


\section{FEDERALISMO E DIREITOS HUMANOS FUNDAMENTAIS - EVOLUÇÃO HISTÓRICA DO ESTADO DE DIREITO, IDEOLOGIAS POLÍTICAS, GOLPES DE ESTADO E OS FUNDAMENTOS \\ DO ESTADO FEDERAL}

relacionados no tríplice chamamento da Revolução Francesa: "Liberdade, igualdade e fraternidade (solidariedade)". Segundo Vladmir da Silveira e Maria Rocasolano (2010, p. 177), "a terceira geração sintetiza os direitos da primeira e da segunda gerações sob o viés de solidariedade, adensando-os numa perspectiva de equilíbrio de poder - inclusive ideológico em favor do ser humano".

Nessa terceira geração/dimensão de direitos, estariam relacionados como direitos da solidariedade: direito à paz, à democracia, ao desenvolvimento, ao meio ambiente equilibrado etc $^{20}$. Tais direitos, reconhecidos em âmbito internacional, estariam em vias de consagração no Direito Constitucional (FERREIRA FILHO, 2012, p. 322). Tal processo de constitucionalização de normas de direito internacional não poderia deixar de influenciar no federalismo.

No tocante aos direitos à democracia e à paz, a Lei Fundamental de Bonn, constituição federal alemã promulgada em 1950, encarregou-se da tarefa de redemocratização do país pós regime nazista. Nesse contexto, o princípio federativo era fundamental para o assentamento de uma democracia estável na Alemanha (ALMEIDA, 2013, p. 37). Sob o ângulo do direito à paz, a manutenção da democracia por meio da divisão espacial do poder evitaria (ou, no mínimo, dificultaria) a instauração de um governo totalitário centralizador tendente a provocar guerras e violar direitos humanos.

O direito ao desenvolvimento foi reconhecido internacionalmente em 1986, quando foi adotada pela ONU a Declaração sobre o Direito ao Desenvolvimento por 146 Estados, com um voto contrário (EUA) e 8 abstenções. De fato, a declaração sobre o direito ao desenvolvimento é uma decorrência lógica do art. 28 da Declaração de Direitos Humanos, que dispõe: "Toda pessoa tem direito a uma ordem social e internacional em que os direitos e liberdades estabelecidos na Declaração possam ser plenamente realizados”. A declaração da ONU de 1986 reconhece o direito ao desenvolvimento nas ordens jurídicas internacional e nacional, revelando um dever do Estado de não somente cooperar com outros países para que esses também obtenham o desenvolvimento (art. $\left.3^{\circ}\right)^{21}$, mas igualmente promover o

\footnotetext{
${ }^{20}$ Não se ignora a posição de outros autores que reconhecem outras gerações de direitos. Paulo Bonavides (2004, p. 571), por exemplo, defende como direitos da quarta geração: o direito à democracia, o direito à informação e o direito ao pluralismo.

21 Artigo $3^{\circ}$. \$1. Os Estados têm a responsabilidade primária pela criação das condições nacionais e internacionais favoráveis à realização do direito ao desenvolvimento. §2. A realização do direito ao desenvolvimento requer pleno respeito aos princípios do direito internacional, relativos às relações amistosas de cooperação entre os Estados, em conformidade com a Carta das Nações Unidas. §3. Os Estados têm o dever de
}

Rev. de Teorias e Filosofias do Estado | e-ISSN: 2525-9652 | Porto Alegre | v. 4 | n. 2 | p. 90 - 110 | Jul/Dez. 2018 
desenvolvimento a todos internamente $\left(\operatorname{art} .8^{\circ}\right)^{22}$. Declarou-se ainda $\mathrm{o}$ caráter de indivisibilidade e interdependência dos direitos humanos $\left(\operatorname{art.} 6^{\circ}\right)^{23}$.

Dentro da estrutura da federação, o direito ao desenvolvimento já se manifestava nas pretensões dos estados de forma anterior a tal declaração da ONU. Planos de desenvolvimento regional, na fase de federalismo cooperativo, eram muito comuns entre as políticas publicas desenvolvimentistas dos governos do século XX. Paulo Bonavides (2000, p. 246) aponta para os auxílios financeiros e projetos administrativos do governo federal em favor de Estadosmembros que foram essenciais tanto para o interesse regional como para o nacional: nos Estados Unidos, o Projeto do Vale do Tennessee (1933); e, no Brasil, a extração do petróleo da Bahia (1939), a eletrificação do Nordeste mediante a companhia hidrelétrica de São Francisco (1948), bem como os planos regionais de desenvolvimento como o SUDENE (1959) e o SUDAM (1966).

A Constituição Federal de 1967/69 previa planos de desenvolvimento regional, incumbindo à União estabelece-los e executá-los (art. 8º XIII). Obrigava-se ainda o orçamento a ter dotações plurianuais para a execução dos planos de valorização das regiões menos desenvolvidas do País (art. 65, §6º). A Constituição Federal de 1988 foi além e fez da redução de desigualdades regionais um dos objetivos fundamentais da República Federativa do Brasil (art. 3ㅇ, III) e um dos princípios da ordem econômica (art. 170, VII). Constitucionalizou, ainda, a Região no art. 43 do texto constitucional, visando ao desenvolvimento e à redução das desigualdades regionais mediante incentivos regionais e articulação entre planos políticos nacionais e regionais.

Em relação ao direito ao meio ambiente, a Constituição de 1988, destinou o artigo 225 de seu texto para sua proteção. Impõe-se ao Poder Público e à sociedade o dever de defendê-lo e preservá-lo para as presentes e futuras gerações. Tal mandamento constitucional

cooperar uns com os outros para assegurar o desenvolvimento e eliminar os obstáculos ao desenvolvimento. Os Estados deveriam realizar seus direitos e cumprir suas obrigações, de modo tal a promover uma nova ordem econômica internacional, baseada na igualdade soberana, interdependência, interesse mútuo e cooperação entre todos os Estados, assim como a encorajar a observância e a realização dos direitos humanos.

${ }^{22}$ Artigo $8^{\circ}$. §1. Os Estados devem tomar, em nível nacional, todas as medidas necessárias para a realização do direito ao desenvolvimento, e devem assegurar, inter alia, igualdade de oportunidade para todos no acesso aos recursos básicos, educação, serviços de saúde, alimentação, habitação, emprego e distribuição equitativa da renda. Medidas efetivas devem ser tomadas para assegurar que as mulheres tenham um papel ativo no processo de desenvolvimento. Reformas econômicas e sociais apropriadas devem ser efetuadas com vistas à erradicação de todas as injustiças sociais. §2. Os Estados devem encorajar a participação popular em todas as esferas, como um fator importante no desenvolvimento e na plena realização de todos os direitos humanos.

${ }^{23}$ artigo $6^{\circ}$. [...]. \$2, dispõem: "Todos os direitos humanos e liberdades fundamentais são indivisíveis e interdependentes; atenção igual e consideração urgente devem ser dadas à implementação, promoção e proteção dos direitos civis, políticos, econômicos, sociais e culturais".

Rev. de Teorias e Filosofias do Estado | e-ISSN: 2525-9652 | Porto Alegre | v. 4 | n. 2 | p. 90 - 110 |

Jul/Dez. 2018 


\section{FEDERALISMO E DIREITOS HUMANOS FUNDAMENTAIS - EVOLUÇÃO HISTÓRICA DO ESTADO DE DIREITO, IDEOLOGIAS POLÍTICAS, GOLPES DE ESTADO E OS FUNDAMENTOS \\ DO ESTADO FEDERAL}

está em sintonia com a noção de desenvolvimento sustentável da Comissão Mundial sobre Meio Ambiente e Desenvolvimento, que a define como o "desenvolvimento que atende às necessidades do presente, sem comprometer a capacidade das futuras gerações atenderem às suas próprias necessidades”, na definição. Na estrutura do Estado federal brasileiro, colocouse a proteção ao meio ambiente nas competências comum e legislativa concorrente da União, dos Estados, do Distrito Federal e dos Municípios (art. 23, VI; e art. 24, VI).

Após esse breve esforço histórico, o que se nota é que o federalismo é afetado pelas gerações de direitos humanos fundamentais, conjecturas sociais e econômicas, ideologias políticas e golpes de estado ao longo da história. A federação nasce vinculada à ideia de Estado de direito, adaptando-se de acordo com as novas demandas de cunho socioeconômico e socioambiental do Estado moderno.

\section{CONCLUSÃO}

Somente se pode falar em federalismo com o advento do Estado de direito. No Estado de não direito, não havia espaço para falar limitação do poder do governante em favor dos indivíduos governados. O Estado de direito é aquele cuja atividade é determinada e limitada pelo direito. Sempre que o Estado de direito e os ideais democráticos são ameaçados, o modelo federativo acaba sendo deformado.

O reencontro do ordenamento constitucional brasileiro com democracia ressuscitou a forma de Estado federal. No Brasil, a Constituição de 1988 passou a conferir maior autonomia aos Estados-Membros, almejando um reequilíbrio federativo. A expansão da autonomia estadual abandona a ideia de federalismo de integração, prevalecendo a ideia de cooperação.

$\mathrm{O}$ federalismo assume historicamente formas diferentes conforme o pensamento político predominante na época e as novas dimensões de direitos que se pretende proteger. $\mathrm{O}$ fundamento principal do Estado federal é a garantia de direitos humanos fundamentais, não podendo (nem devendo) o instituto afastar-se desse pressuposto lógico constitucional.

A ideia da associação entre estados nacionais baseia-se em uma lógica de segurança interna e uma lógica de paz universal. Ressalta-se ainda a dimensão cultural do federalismo uma das principais vantagens do Estado federal em detrimento do Estado unitário é a ideia de que as tradições regionais militam contra a fusão de Estados individuais em uma organização unitária. Fortalece-se, desta forma, o sentimento de defesa das diferenças culturais das diversas entidades dentro da estrutura associativa.

Rev. de Teorias e Filosofias do Estado | e-ISSN: 2525-9652 | Porto Alegre | v. 4 | n. 2 | p. 90 - 110 | Jul/Dez. 2018 
Após esse breve esforço histórico, o que se nota é que o federalismo é afetado pelas diferentes gerações/dimensões de direitos humanos fundamentais, conjecturas socioeconômicas, ideologias políticas e golpes de estado ao longo do tempo. A federação nasce vinculada à ideia de Estado de direito, adaptando-se de acordo com as novas demandas de cunho socioeconômico e socioambiental do Estado moderno.

\section{REFERÊNCIAS}

ALMEIDA, Fernanda Dias Menezes de. Competências na Constituição de 1988. 6. Ed. São Paulo: Atlas. 2013.

BERCOVICI, Gilberto. A Constituição invertida: a Suprema Corte Americana no combate à ampliação da democracia. Lua Nova, n. 89, 2013.

BOBBIO, Norberto. A era dos direitos. Rio de Janeiro: Campus, 1992.

BONAVIDES, Paulo. Ciência política. São Paulo: Helvética Editorial Ltda., 2000.

. Curso de Direito Constitucional. 15a edição. São Paulo: Malheiros, 2004.

. O caminho para um federalismo das regiões. id/496931, 1980.

CANOTILHO, José J. Gomes. Estado de direito. Lisboa: Gradiva, 1999.

CAVALCANTI, Amaro. Regimen federativo e a republica brasileira. Rio de Janeiro: Imprensa Nacional, $1900 . \quad$ Disponível em: <http://www.dominiopublico.gov.br/download/texto/bd000136.pdf>. Acesso em: 24 maio 2018

COMPARATO, Fábio Konder. A afirmação histórica dos direitos humanos - 8. ed. - São Paulo: Saraiva, 2013.

CONTI, José Maurício. Considerações sobre o federalismo fiscal brasileiro em uma perspectiva comparada. Federalismo Fiscal - Questões Contemporâneas, Florianópolis: Conceito Editorial, 2010.

ELY, John Hart. On constitutional ground. Nova Jérsei: Princeton University Press, 1996.

EVANS, Richard J. (2005). The Third Reich in Power. New York: Penguin.

FERREIRA FILHO, Manoel Gonçalves. Curso de direito constitucional.38. ed., São Paulo: Saraiva, 2012.

O poder constituinte. 6. ed. São Paulo: Saraiva, 2014.

HORTA, Raul Machado. Evolução política da dederação. Revista de Ciência Política, v. 3, n. 1, p. 30-63, 1969. 


\section{FEDERALISMO E DIREITOS HUMANOS FUNDAMENTAIS - EVOLUÇÃO HISTÓRICA DO ESTADO DE DIREITO, IDEOLOGIAS POLÍTICAS, GOLPES DE ESTADO E OS FUNDAMENTOS \\ DO ESTADO FEDERAL}

IZECKSOHN, Vitor. Escravidão, federalismo e democracia: a luta pelo controle do Estado nacional norte-americano antes da Secessão. Topoi (Rio de Janeiro), v. 4, n. 6, p. 47-81, 2003. KANT, Immanuel. A paz perpétua: um projecto filosófico. A Paz Perpétua e outros opúsculos. Tradução por Artur Morão. Covilhã: 2008.

MARX, Karl; ENGELS, Friedrich. Manifesto comunista. Boitempo Editorial, 2015.

MORAES, Alexandre de. Federação brasileira-necessidade de fortalecimento das competências dos estados-membros. Revista de Direito Administrativo, v. 251, p. 11-27, 2009.

RAMELLA, Pablo A. Replanteo del federalismo. Ediciones Depalma, 1971.

RIKER. William H. The development of American federalism. Kluwer Academic Publishers Group. Springer Netherlands: 1987.

SCHÜTZE, Robert. From dual to cooperative federalism: the changing structure of European law. Oxford University Press, 2009.

SECONDAT, Charles-Louis de - Barão de Montesquieu. O espírito das leis. Trad. Cristina Murachco. São Paulo: Martins Fontes, 1996.

SILVA, José Afonso da. Curso de direito constitucional positivo. São Paulo: Malheiros, 2014. O Estado democrático de direito. Revista de direito administrativo, v. 173, p. 15-24, 1988.

SILVEIRA, Vladmir Oliveira da; ROCASOLANO, Maria Mendez. Direitos Humanos: conceitos, significados e funções. São Paulo: Saraiva, 2010.

SOUZA, Celina. Federalismo, desenho constitucional e instituições federativas no Brasil pós1988. Revista de sociologia e política, v. 24, n. 24, p. 105-122, 2005.

SPIRO, Peter J. The States and International Human Rights, 66. Nova Iorque: Fordham L. Rev. 567, 1997. Disponível em: http://ir.lawnet.fordham.edu/flr/vol66/iss2/9

TAVARES, André Ramos. Curso de direito constitucional. 11. ed. São Paulo: Saraiva, 2013. 